\title{
Ophthalmoscopy: A 7-Step Program
}

\author{
Joseph M. Dooley, Kevin E. Gordon
}

\begin{abstract}
Background: Fundoscopy is viewed as a difficult or impossible task by many students and physicians. We have used a novel seven-step approach to teach trainees to use the ophthalmoscope. The technique is based on the premise that success is most easily achieved if the necessary motor skills are mastered first. A step by step approach will enable others to teach their trainees to attain the ability to routinely view the fundi of their pediatric patients. Methods: Step 1 involves examination of the trainee's fundi to ensure there is no impediment to their success. In Step 2 the student examines the teacher. This identifies major errors. The next step teaches the trainee how to hold the ophthalmoscope. Step 4 gets the learner to read a journal article through the ophthalmoscope. In Step 5 they examine the teacher's eyes again and with a little help they are always successful. In the last two steps an older patient is first examined and finally the student examines a young child. Conclusion: This method differs from most other approaches by leaving the cognitive component of ophthalmoscopy until the student is comfortable with handling the instrument. It has been uniformly successful among our students and residents.
\end{abstract}

RÉSUMÉ: L'ophtalmoscopie : un programme d'enseignement en 7 étapes. Contexte : Plusieurs étudiants et plusieurs médecins considèrent que l'examen du fond d'œil est une tâche difficile sinon impossible. Nous avons utilisé une nouvelle approche en 7 étapes pour enseigner aux étudiants l'utilisation de l'ophtalmoscope. La technique est basée sur le principe que les chances de succès sont plus élevées si les habiletés motrices nécessaires à la tâche sont maîtrisées d'abord. Une approche étape par étape permettra à d'autres d'enseigner à leurs étudiants comment parvenir à visualiser systématiquement le fond d'œil de leurs patients pédiatriques. Méthodes : La première étape consiste à examiner le fond d'œil de l'étudiant pour s'assurer qu'il n'existe pas d'entrave à ce niveau. Dans la deuxième étape, l'étudiant examine le professeur. Ceci permet d'identifier des erreurs majeures. Au cours de l'étape suivante, on enseigne à l'étudiant comment tenir l'ophtalmoscope. À l'étape 4, l'étudiant lit un article de journal à l'aide de l'ophtalmoscope. À l'étape 5, il examine de nouveau les yeux du professeur et, avec un peu d'aide, l'étudiant y parvient toujours. Au cours des deux dernières étapes, l'étudiant examine d'abord un patient plus âgé puis un jeune enfant. Conclusion : Cette méthode diffère de la plupart des autres approches en ce qu'elle reporte la composante cognitive de l'ophtalmoscopie jusqu'au moment où l'étudiant est à l'aise de manipuler l'instrument. Elle remporte toujours du succès auprès de nos internes et de nos résidents.

Can. J. Neurol. Sci. 2008; 35: 237-242

Fundoscopy has been depicted as a forgotten art, ${ }^{1}$ although there is little evidence that use of the direct ophthalmoscope was ever widely practiced. Examination of the fundus is, however, critical to the appropriate assessment of children who are seen within multiple branches of pediatrics. Physicians are hesitant to look in their patients' eyes, as both medical students and senior faculty often lack the skill and confidence needed to use the direct ophthalmoscope. ${ }^{1}$ The reasons for this discomfort include insufficient teaching and exposure during medical school and residency. The difficulties encountered by many trainees are frequently compounded by an inability to merely hold the ophthalmoscope effectively.

Physicians are more likely to reach a correct diagnosis if shown a photograph of retinal pathology than if asked to view the fundus directly. ${ }^{1}$ We believe that this supports our hypothesis that teaching appropriate motor skills must be the initial step in teaching physicians to master the ophthalmoscope.

All residents in pediatrics, adult neurology, psychiatry and first-year ophthalmology at Dalhousie University do a clinical rotation on our pediatric neurology service. These residents are graduates of both Canadian and foreign medical schools. We also host a variety of elective Canadian and international medical students. Like others we have been impressed that, almost universally, fundoscopy is done poorly, if at all. ${ }^{2}$

We have used a novel approach to teach fundoscopy, which is rooted in a motor learning paradigm. Through a series of maneuvers, students and physicians at various levels of training can be taught to successfully accomplish the skills needed to competently view the fundi of children. If this skill is learned early in the student's training, they have the added advantage of

From the Pediatric Neurology Division, Dalhousie University and IWK Health Centre, Halifax, Nova Scotia, Canada.

Received July 19, 2007. Final Revisions Submitted November 8, 2007. Reprint requests to: J.M. Dooley, Pediatric Neurology Division, Dalhousie University and IWK Health Centre, 5850/5980 University Avenue, Halifax, Nova Scotia, B3K 6R8, Canada. 
viewing many fundi before completing their residency and thus enhance their confidence in correctly diagnosing abnormalities during their careers. Without this skill, physicians run the risk of either missing important clinical findings during their subsequent years of practice or of compensating by ordering unnecessary tests.

\section{METHODS}

In order to conquer the demons of fundoscopy our program brings each student through the following seven steps.

Step 1: Examine the student's eyes: The teaching session should begin with an assessment of the individual student's eyes. In general students, who do not have astigmatism and wear corrective lenses less than $+/-4$ diopters (D), should remove their glasses. By examining the trainee's eyes you establish if he/she has any ocular disorder which might prevent successful fundoscopy. It also establishes which lens setting is appropriate for them when they examine your eyes in Step 2. We have been impressed by how many students have undiagnosed strabismus, amblyopia or other ophthalmologic disorders.

Step 2: The student examines your eyes: The student is next asked to examine your fundus, and particularly your optic disc. First position yourself so that your eye is at the same level as the student's. This ensures that your optic disk will be on the horizontal meridian as the student approaches you. By being examined by the learner you will observe the errors in their technique.

Among the most commonly encountered problems are: 1) Moving the ophthalmoscope relative to the body, thus allowing the light to stray from the desired viewing area, 2) Standing too far away from the patient's eye and therefore reducing the field of view. This is extremely difficult for some students, especially early in their training, who feel uncomfortable getting very close to a patient or for those with hyperekplexia, whose startle response may be elicited by getting too close. 3) Some learners initially find it difficult to look through the ophthalmoscope with their non-dominant eye. They must appreciate that looking at the left eye with their right eye, and visa versa, will result in blocking the child's field of vision with their fixating eye and will compromise the patients' ability to keep their eyes still. Students should also be reminded that allowing face to face contact increases the spread of airborne infection between patient and examiner. It may be helpful to reverse roles for a moment to demonstrate that as you approach using the wrong eye you not only block their fixating eye but also present an intimidating face to face proximity. 4) If the student insists on closing the eye which is not looking through the ophthalmoscope, it must be held open at least until they have established that they are in the correct position to view the fundus. Premature closure will allow them to get lost in space, as the ophthalmoscope light scans the forehead, nose etc. 5) Occluding the patient's fixating eye by allowing "big hair" to intrude into their field of vision. Those with extravagant hair should find some method of holding it out of the way. After the student has examined your eye, the path tracked by their attempt can be confirmed by closing your eyes. A brief "after-image" can be perceived as a light track across your retina. Those who have been wildly scanning around your retina will leave a criss-cross pattern compared to students who focus directly on the disc who will leave a single spot of light. Having the student look in your eye identifies his/her area of major weakness and allows a more focused approach to remediation. Occasionally a student may be able to skip some of the following steps, but most benefit from the full program.

Step 3: Handling the ophthalmoscope: When holding the ophthalmoscope the student must ensure that the knuckles do not protrude and press on the face of the patient (Figure 1). In order to prevent the ophthalmoscope from moving relative to the face and visual axis, it should be stabilized by resting your hand against at least one of the forehead and upper or lower cheek (Figure 2). This also helps minimize the effect of physiological tremor. The student should hold the ophthalmoscope with the ipsilateral hand, e.g. the left hand holds the ophthalmoscope to look with the student's left eye at the patient's left eye. After demonstrating the ability to hold the ophthalmoscope correctly, the student then practices switching, and re-establishing the grip from hand to hand.

Step 4: Looking through the ophthalmoscope: When the learner is comfortable holding the ophthalmoscope with either hand, they should be prevented from their inevitable desire to immediately embark on fundoscopy, until they have also demonstrated their ability to see clearly through the instrument. This is easily achieved by getting the student to read a journal article through the ophthalmoscope. The optimal position to begin reading and therefore to place the article is established by having the student stand at the wall and mark the level of their pupil. A page from the journal is then taped to the wall with the upper margin approximately two inches above the level of the
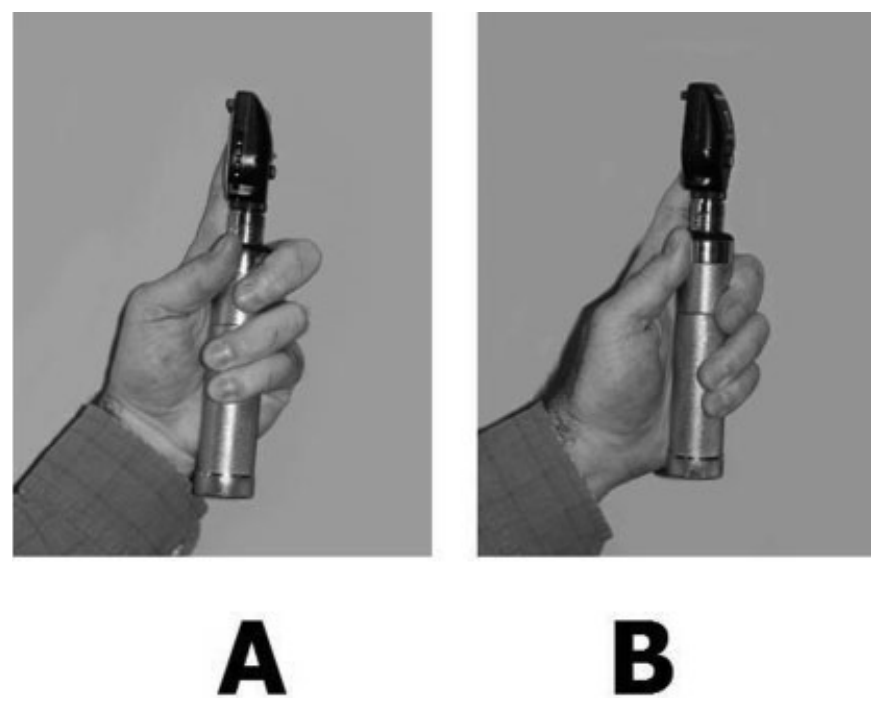

Figure 1: Holding the ophthalmoscope incorrectly, with knuckles protruding, (A) and correctly $(B)$ 


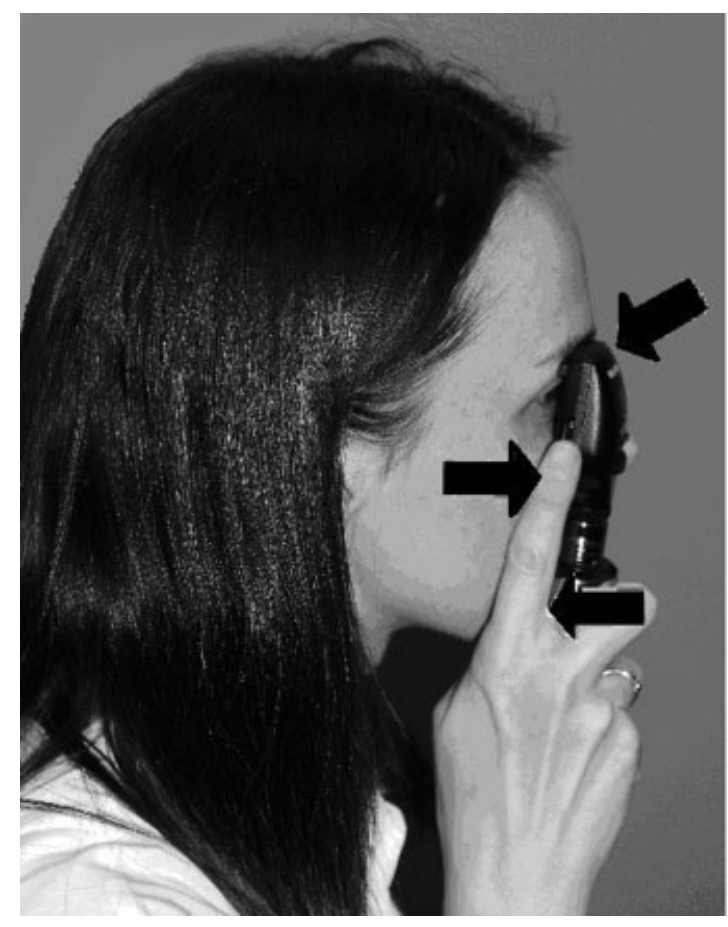

Figure 2: Holding the ophthalmoscope correctly requires stabilizing it by anchoring it to the forehead, cheek and chin (arrows) optic disc. The disc is located $10^{\circ}$ to $20^{\circ}$ temporal to the patient's line of sight. For many students and residents, who have always previously settled for "red reflex seen", this will be the first time they have clearly seen an optic disc and is a "eureka" moment. Stress that they were successful because they approached from the correct angle. Following their success at reading the journal article, they have discovered that maintaining the light in the centre of the field of vision is essential. They easily apply this principle to view the remainder of your fundus. They should be instructed to view the optic disc, fovea/macular area and retinal arteries and veins.

They should check for elevation of the optic disc. Papilledema, with elevation of the optic disc can be quantified by determining the change in lens needed to focus on the top of the disc. Each $3 \mathrm{D}$ change in lens equals $1 \mathrm{~mm}$ elevation. Therefore if the retinal surface is seen best with a $-1 \mathrm{D}$ lens and the top of the disc requires a $+2 \mathrm{D}$ lens, the disc is elevated $1 \mathrm{~mm}$. The central retinal arteries are two-thirds the size of the veins and appear more red than the "bluish" veins. The macula is about the size of the optic disc, has a shimmering appearance in children and is darker than the surrounding retina. It is normally seen about two disc diameters temporal to the edge of the optic disc. The fovea is in the middle of the macula and is free of blood vessels. It has a small white reflex in children. Examination of the macula is usually left until the end of the assessment as it causes photophobia in many children. Viewing the macula and

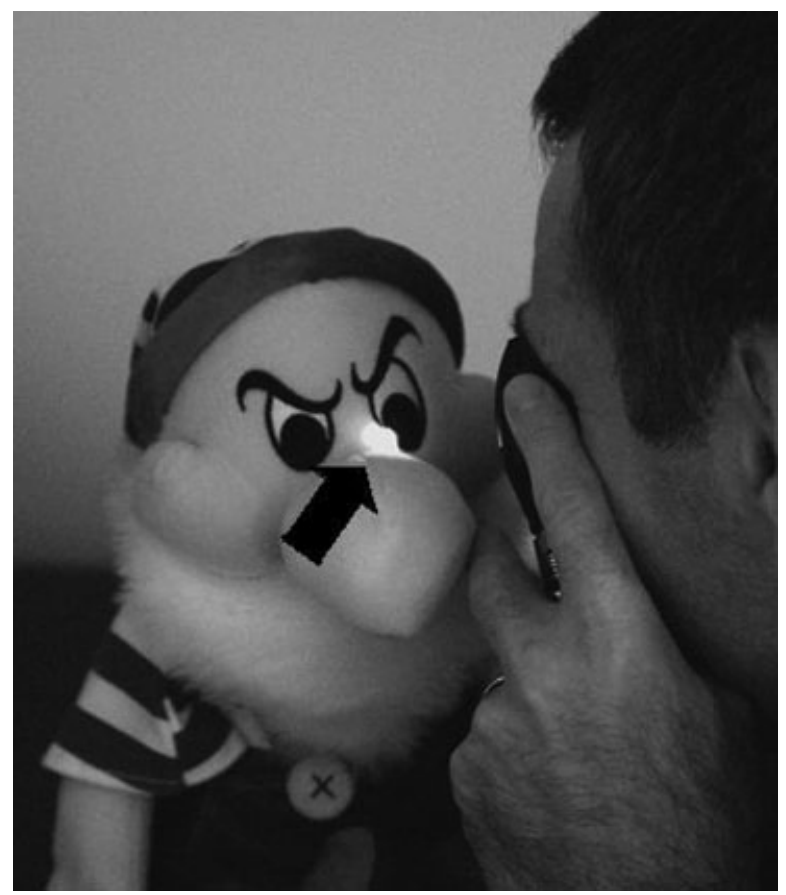

student's pupil. As many trainees have difficulty suppressing their dominant eye, the ophthalmoscope lens should be set at about +15 to $+20 \mathrm{D}$ and the room should be darkened. In this setting they are forced to move close to the page and they will be unable to read with the other eye. Similarly they learn that the ophthalmoscope must be anchored to the face and that they must keep the light in the middle of the viewing area in order to read. They also establish the need to move laterally and vertically in order to maintain the light in the viewing area as they progressively read the page. Moving the ophthalmoscope, without keeping the instrument anchored to the face will result in failure as the viewed area 'blacks out' (Figure 3). As the remainder of the article is read, more time should be spent using the non-dominant eye and the light in the room should be gradually increased. This exercise should be repeated until the students are comfortable with their ability to read through an ophthalmoscope with either eye.

Step 5: Looking at your fundus again: It is essential that the student should achieve immediate success in order to ensure their ongoing enthusiasm. Modify your height so your pupils are at the same level as theirs and, with their permission, guide their shoulders to move them into the correct position to see your fundus. This is especially important if the student must close the 'non-ophthalmoscope' eye. As described above during the initial attempt to see your fundus, the teacher can easily determine where the light falls on the fundus and by moving the student's shoulders the ophthalmoscope light beam can be directed to your
Figure 3: Allowing the ophthalmoscope's orientation to stray from the viewing axis allows the light to deviate from the area being seen. "Everything goes black" 
fovea are particularly challenging when the pupil is not dilated, as light in this area causes maximal constriction of the pupil through the pupillary light reflex.

Step 6: Examining a patient: The student is now ready to examine a teenage patient. Remind them to: a) use the ipsilateral rule (right hand using right eye to look in right eye), b) ensure that the patient's pupil is at the same level as theirs, c) allow unimpeded fixation by the patient on a spot at the same level as the pupil, d) approach along a line that is $10^{\circ}-20^{\circ}$ lateral or temporal on the patient's visual axis and e) allow patients with high refractive errors or high astigmatism to wear their corrective lenses. It should be emphasized that the only difference between looking at your fundus and that of a child, is the importance of setting the patient up for success. For trainees who must close their other eye during fundoscopy, it will be imperative that they either keep the eye open until they are in position or that they place their free hand on the patient's shoulder to maintain a sense of their position relative to the patient's eye. This technique can be expected to result in success in patients over six years of age. In clinical practice it is often difficult to get the tall or short patient's pupil at the same level as yours. Students should be taught to use the point of fixation to their advantage. By changing the angle of trajectory of the patient's visual axis, a tall patient can be asked to focus at an object lower than their pupil height and conversely a shorter child can look at a higher point (Figure 4). This allows the trainee to remain standing at normal height during the examination.

Step 7: Examining the younger patient: When the trainee is comfortable with their success in the preceding steps, they should attempt fundoscopy on the younger child. Most young patients do not tolerate dilatation of the pupils very well and the smaller round light on the ophthalmoscope should be used as this will allow more light to travel through the pupil with less reflection from the iris. The only modification necessary is to set up the patient in a slightly different way.

Age 21/2 to 6 years: The major challenge in children of this age, and for those who are slightly older but less cooperative, is

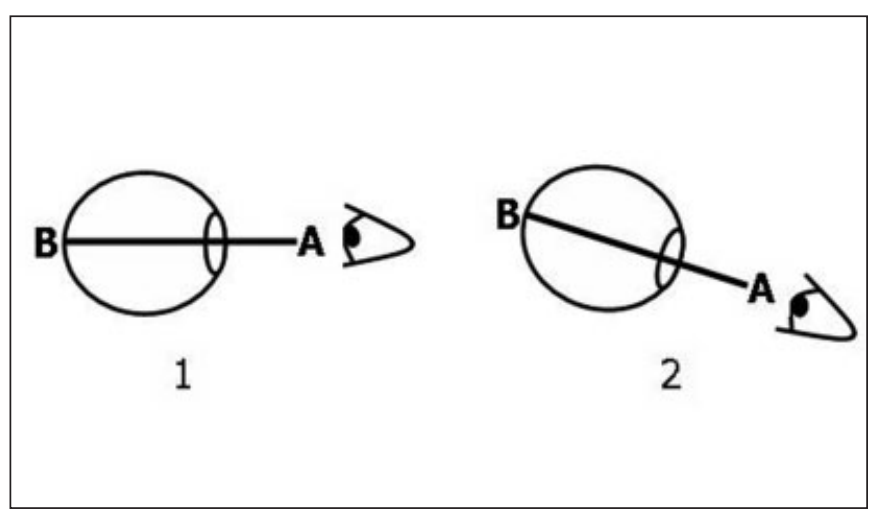

Figure 4: By changing the point of fixation for the patient, the examiner can stand at their normal height for tall or short patients persuading them to maintain fixation for long enough to allow fundoscopy. Seat the child so their pupil height is similar to your own and reduce the ambient light to allow your pupils to dilate. The parent is then asked to stand behind you, as you explain to the child that parents are strictly forbidden to carry out some activity, such as wiggling their noses or protruding their tongues. The parent is warned that they will be "in big trouble" if they break the rules. With the parent standing across the room, the child is asked to watch and report if their mother does the specified activity. Children tend to be either horrified by their parent's transgression of the rules or delighted by the opportunity to get their mother into trouble. In either situation, you can feign anger and give the parent a second chance while you view the other fundus. This maneuver has been spectacularly successful in convincing children to remain focused on one location.

Age 3 months to 21/2 years: In this age group it may be prudent to leave fundoscopy until the end of the examination, if you believe it could be upsetting. The child who has only one parent in attendance should be seated on your desk, thus allowing you to examine while you remain seated. The ambient light should be dimmed but the room should not be completely dark, as this will alarm most toddlers. The parent should stand behind you and repeatedly call their child's name or talk to them, to get them to fixate on the parent's face. Alternately, the parent can hold the child so that the head is "cuddled" against the shoulder. This allows the head to be stabilized without upsetting the child. A helper, such as the other parent if present or the clinic nurse, should then hold an interesting toy in the desired position. Even with this set-up, speed and competence are necessary for success. Students should remember that the disc is $10^{\circ}-20^{\circ}$ temporal to the midline and they will be more likely to see it during the 200$250 \mathrm{msec}$. pauses between saccades if they take advantage of being in the correct position to start. Students who have practiced the initial five steps repeatedly are more likely to be successful.

Birth to 3 months: Babies can usually be persuaded to open their eyes if given something to suck while their heads are held with the neck in the neutral position. In neonates the middle finger can be placed in the baby's mouth with the index and ring fingers on each cheek. In this position the head can be moved easily to take advantage of the doll's eye reflex. Fundoscopy may be difficult in neonates as their small pupil size is usually in the range of $3.6 \mathrm{~mm} \pm 0.9$. For the baby beyond the neonatal period, the baby should be held in the mother's lap facing you. The other parent or nurse stands behind you and attracts the child with voice, bright toys, waving or whatever is needed to encourage the child to fixate. By being correctly positioned from the start, the student is more likely to get a brief view of the fundus and particularly the disc.

The Panoptic Ophthalmoscope: Although the conventional direct ophthalmoscope has the disadvantage of providing a limited $\left(5^{\circ}-10^{\circ}\right)$ field of view, it is essential to master its use as it is the instrument provided by most Emergency Departments and hospital wards. Hopefully with time the Panoptic Ophthalmoscope (PO) will become more readily available in our hospitals. The Panoptic (PO; Welch-Allyn, Skaneatles Falls, NY, USA) is a new direct ophthalmoscope which uses 'axial point source' optics to give a wider field of view $\left(25^{\circ}\right)$ and a $26 \%$ increase in magnification compared to the conventional ophthalmoscope. Medical students find this an easier instrument 


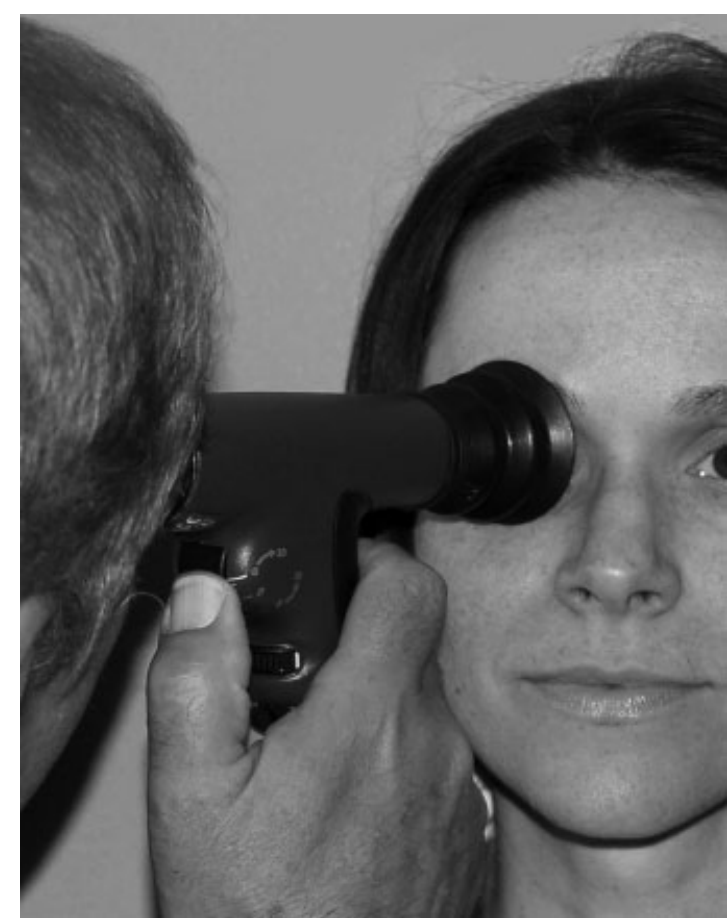

Figure 5: The pan-optic ophthalmoscope increases the magnification and field of view and establishes the correct position for viewing

to use. ${ }^{3}$ The PO also simplifies a number of the steps needed to successfully view the fundi. The correct distance for viewing is further from the patient and is mandated by approaching until the rubber adapter covers the patient's eye. The focusing wheel can be adjusted to focus on the iris before fundoscopy starts and usually does not need to be altered when viewing the retina (Figure 5). Obviously if abnormalities are suspected the $45^{\circ}$ angle afforded by indirect ophthalmoscopy, especially when accompanied by pupillary dilatation, allows the physician a much better view of the fundus.

\section{Discussion}

Direct fundoscopy has been identified by the Association of University Professors of Ophthalmology (AUPO) as a basic competence which should be part of the repertoire of all physicians. ${ }^{4,5}$ It remains, however, an elusive skill and most program directors believe that less than half of their residents meet these standards on completing medical school. ${ }^{4}$ Similarly $13.6 \%$ of pediatric program directors did not believe their trainees met the AUPO standards. ${ }^{4}$ Although alarming, these statistics may be optimistic.

In a review of hospital case notes, Roberts et al found that only 3 of 100 patients had had fundoscopy. ${ }^{1}$ In this British study of 41 senior and junior doctors working in general and geriatric medicine, all felt that fundoscopy was important but it was routinely performed by only three. In addition only $44 \%$ were confident in their skills, $73 \%$ believed they had insufficient training and $97 \%$ felt their skills could be improved. ${ }^{1}$ A study of 133 primary care practitioners showed similar results. ${ }^{6}$ Only $22 \%$ felt their undergraduate ophthalmic medical education was adequate, $44 \%$ felt uneasy or very uneasy with the ophthalmoscope and this was particularly true for younger physicians and those practicing in non-teaching settings. Among pediatricians the findings have been similar. The mean selfreported confidence in performing fundoscopy was 1.9 , on a scale of 0 to 7 , among 11 pediatric residents and 5 senior pediatricians. ${ }^{7}$ The difficulties appear to begin within medical school. In a recent survey of Canadian medical students, $47 \%$ of third and fourth year students reported that they were 'not at all' or only 'a little' confident in performing direct ophthalmoscopy on an undilated pupil and $87 \%$ were "quite" or "extremely" interested in further practice and training. ${ }^{8}$ Although there is a great similarity in ophthalmology curricula among Canadian medical schools, overall $31 \%$ do not receive clinical exposure to ophthalmology during their training. ${ }^{9}$

The art of fundoscopy must begin with the basic motor skills needed to successfully look through an ophthalmoscope. The trainee must first master the serial motor skills needed to hold the instrument correctly. Success depends on achieving proficiency in several discrete actions which must be performed in a specific sequence. Motor tasks can be classified as open or closed, with the latter occurring in a stable and predictable environment. Students learn closed motor skills most effectively with repetition in a fixed set of environmental conditions. ${ }^{10}$ Learning the cognitive or diagnostic aspects is of little value if the student does not accomplish the necessary motor component.

Providing the opportunity to repetitively use the ophthalmoscope in a controlled setting will enhance success. As students are particularly uncomfortable using their non-dominant hand, emphasis must be placed on providing the opportunity to practice with both hands. ${ }^{8}$ Ideally students should have ready access to ophthalmoscopes to facilitate ongoing practice. Historically, students have been instructed to buy an expensive halogen ophthalmoscope, although acquiring an ophthalmology textbook was always optional. ${ }^{11}$ With the increasing costs associated with attending medical school, many students seem ready to forego this expense. In a recent survey more than onethird of Canadian medical students did not own an ophthalmoscope. ${ }^{8}$

There have been numerous articles which have attempted to help the learner use the ophthalmoscope. ${ }^{11-18}$ Devices which have been employed include plastic canisters with photos of the fundus ${ }^{16}$ and table-tennis balls with words or photographs inside. ${ }^{17}$ Most of these approaches have focused on the cognitive components of fundoscopy. In contrast, we believe that difficulties with the motor components primarily hinder success. Our seven-step program is based upon knowing the anatomy of the eye, the physiology of eye control and the developmental behavior of children. As with most motor learning paradigms, success is easier to achieve if the task is divided into manageable subtasks. Each step builds upon the skills acquired in the previous step, with the goal of progressive competency.

We emphasize the basics of using the ophthalmoscope as the first requirement. Students quickly learn that the field of view with direct ophthalmoscopy is limited by the most oblique ray of 
light that exits the patient's pupil and enters the examiner's pupil. While dilatation of the pupils will increase the field of view, this is often not practical in pediatrics and is often inappropriate in pediatric neurology. Trainees can compensate somewhat for this limitation by getting as close as possible to the patient. ${ }^{19}$ Knowing the anatomy will clarify that the optic disc will be most readily and quickly seen if the student approaches along an axis that is $10^{\circ}$ through $20^{\circ}$ temporal to the midline. Students achieve early success if they limit their initial movements to a horizontal plane. With practice they learn to take advantage of the pauses between saccades in the uncooperative child.

The self-assurance associated with reading a journal article through the ophthalmoscope empowers the student and enhances their confidence in approaching the fundus. We have had universal success in teaching competent fundoscopy to date, with all residents who have completed the program demonstrating their competence with the ophthalmoscope. We disagree with the American Academy of Pediatrics, which suggests that it "may be possible to perform ophthalmoscopy on a cooperative four-yearold and that most children should be able to cooperate by five years of age". ${ }^{20}$ We expect our trainees to achieve success in all pediatric patients, with the exception of the most uncooperative.

Medical students are universally motivated to learn what is needed for examinations. The incentive to learn fundoscopy may be further undermined by the examination format used in many schools. Although objective structured clinical examinations (OSCE) are in common use, testing students by asking them to recognize retinal pathology in slides or photographs ignores the skills necessary to see the fundus. Alternate methods of assessing students in the OSCE setting have been suggested. ${ }^{21}$ Clearly examinations should include an evaluation of the trainee's ability to actually use the ophthalmoscope.

Unfortunately our curricula to date seems to have failed to provide the necessary skills and confidence which physicians want. The maxim that "many look but few see" has been rewritten for ophthalmoscopy as "few see because few look". 2

Training can be effective and, following formal ophthalmoscope training, students do show persistent improved proficiency over at least a two month period. ${ }^{22}$ Our approach is simple but effective. The major drawback is the demand on faculty time because of the requirement for initial individual instruction. We believe this is a worthwhile investment that could reap significant returns by producing physicians with the confidence and skills to examine the fundi of children.

\section{REFERENCES}

1. Roberts E, Morgan R, King D, Clerkin L. Fundoscopy: a forgotten art. Postgrad Med J. 1999;75:282-4.

2. Fred HL. Requiem for the ophthalmoscope. Hosp Pract. 1994; 29:37-8.

3. McComiskie JE, Greer RM, Cole GA. Panoptic versus conventional ophthalmoscope. Clin Experiment Ophthalmol. 2004;32:238-42.

4. Stern GA. Teaching ophthalmology to primary care physicians. Arch Ophthalmol. 1995;113:722-4.

5. Bradford CA. Basic ophthalmology for medical students and primary care residents. 8th ed. Am Academy of Ophthalmology. 2004:19-24.

6. Shuttleworth GN, Marsh GW. How effective is undergraduate and postgraduate teaching in ophthal-mology? Eye. 1997;11:744-50.

7. Morad Y, Barkana Y, Avni I, Kozer E. Fundus anomalies: what the pediatrician's eye can't see. Int J Qual Health Care. 2004;16: 363-5.

8. Gupta RR, Lam WC. Medical students' self-confidence in performing direct ophthalmoscopy in clinical training. Can J Ophthalmol. 2006;41:169-74.

9. Bellan L. Ophthalmology undergraduate education in Canada. Can J Ophthalmol. 1998;33:3-7.

10. Schmidt RA, Wrisbwerg CA. Motor learning and human performance. 3rd ed. Windsor: Human Kinetics; 2004.

11. Miller D. A teaching eye model for ophthalmoscopy. J Med Educ. 1981;56:671-2.

12. Garber N. Performing direct ophthalmoscopy. J Ophthalmic Nurs Technol. 2000;19:120-9.

13. Sit M, Levin AV. Direct ophthalmoscopy in pediatric emergency care. Pediatr Emerg Care. 2001;17:199-204.

14. Chung KD, Watzke RC. A simple device for teaching direct ophthalmoscopy to primary care practioners. Am J Ophthalmol. 2004;138:501-2.

15. Bradley P. A simple eye model to objectively assess ophthalmoscopic skills of medical students. Med Educ. 1999;33:592-5.

16. Boyd-Monk H. How to use a direct ophthalmoscope. Occup Health Nurs. 1983;31:13-6.

17. Reich JA, Colvin JL. Practical procedures: ophthalmoscopy. Aust Fam Physician. 1980;9:509-12

18. Waring GO, Harris R, Walters RF, Berris C. Clinical ophthalmology instruction for medical students. Surv Ophthalmol. 1977;22:106-12.

19. Snead MP, Rubinstein MP, Jacobs PM. The optics of fundus examination. Surv Ophthalmol. 1992;36:439-45.

20. Committee on Practice and Ambulatory Medicine, Section on Ophthalmology. Eye examination and vision screening in infants, children and young adults. Pediatrics. 1996;98:153-7.

21. Levy A. Churchill AJ. Training and testing competence in direct ophthalmoscopy. Med Educ. 2003;37:483-4.

22. Cordeiro MF, Jolly BC, Dacre JE. The effect of formal instruction in ophthalmoscopy on medical student performance. Med Teach. 1993;15:321-5. 